\title{
Intraoperative use of spectral-domain optical coherence tomography during Descemet's stripping automated endothelial keratoplasty
}

This article was published in the following Dove Press journal:

Clinical Ophthalmology

22 March 2012

Number of times this article has been viewed

\author{
Chelvin CA Sng ${ }^{1,2}$ \\ Federico Luengo Gimeno' \\ Jodhbir S Mehta ${ }^{1,2}$ \\ Hla Myint Htoon' \\ Donald T Tan ${ }^{1,2}$ \\ 'Singapore Eye Research Institute \\ and Singapore National Eye Center, \\ ${ }^{2}$ Department of Ophthalmology, \\ National University Health System, \\ Singapore
}

Purpose: To evaluate the intraoperative changes in the donor lenticule, recipient cornea, and the reduction of interface fluid thickness during Descemet's stripping and automated endothelial keratoplasty with EndoGlide ${ }^{\mathrm{TM}}$ (Angiotech Pharmaceuticals Inc, Vancouver, Canada) donor insertion, using intraoperative spectral-domain optical coherence tomography.

Methods: Prospective observational case series of patients underwent Descemet's stripping and automated endothelial keratoplasty using the EndoGlide inserter. Spectral-domain optical coherence tomography (iVue; Optovue Inc, Fremont, CA) with a handheld probe was used to image the cornea and anterior chamber. Standardized software was used to measure interface fluid gap, host cornea, and donor lenticule thicknesses during the following surgical stages of Descemet's stripping and automated endothelial keratoplasty: (1) after donor insertion and immediately before full air tamponade; (2) after air tamponade and expression of fluid from venting incisions; (3) at 6 minutes of air tamponade; and (4) at 10 minutes of air tamponade.

Results: Ten patients with a mean age of $74.9 \pm 11.8$ years were recruited. Spectral-domain optical coherence tomography measurements of the interface fluid gap after fluid was expressed through the venting incisions $(P<0.001)$, at 6 minutes of air tamponade $(P<0.001)$ and at 10 minutes of air tamponade $(P<0.001$ and $P=0.001$, respectively), were significantly decreased compared to the measurements immediately before air tamponade. Donor thickness increased significantly at 6 minutes of air tamponade $(P=0.004)$ but reduced by 10 minutes compared to immediately before air tamponade.

Conclusion: Significant intraoperative changes in the donor, recipient cornea, and interface fluid thickness occurred following endothelial keratoplasty donor insertion.

Keywords: Descemet's stripping and automated endothelial keratoplasty, spectral-domain optical coherence tomography

\section{Introduction}

Descemet's stripping and automated endothelial keratoplasty (DSAEK) has rapidly replaced penetrating keratoplasty as the preferred surgical treatment for endothelial disorders. ${ }^{1}$ Compared to penetrating keratoplasty, the advantages offered by DSAEK include faster visual rehabilitation, reduced postoperative astigmatism, and lower rates of wound dehiscence. ${ }^{1-3}$ However, graft detachment is the most common complication encountered in DSAEK, with a reported incidence ranging from $17.5 \%$ to $50 \%$. ${ }^{3-5}$ Price and Price have shown that intraoperative measures to minimize the amount of interface fluid between the recipient cornea and the donor, including corneal venting incisions which allow the removal of interface fluid and a longer duration of air tamponade, lowered the initial rates of graft detachment. ${ }^{6}$
Correspondence: Donald T Tan Singapore National Eye Centre, II Third Hospital Avenue, Singapore I6875 I

Tel +6563228384

Fax +6562277290

Email donald.tan.t.h.@snec.com.sg 
Optical coherence tomography (OCT) is a noncontact optical system that uses low-coherence interferometry to obtain in vivo cross-sectional images of the eye. ${ }^{7}$ Time-domain OCT has been widely used in the evaluation of both the posterior and the anterior segments, ${ }^{8-16}$ including the analysis of DSAEK grafts postoperatively. ${ }^{17}$ The recent development of spectral-domain OCT (SD-OCT) now allows faster image acquisition and a broadband light source provides improved spatial resolution, enabling better detection of different interfaces within ocular tissues, eg, following the creation of laser-assisted in situ keratomileusis flaps. ${ }^{11}$ SD-OCT has also been used during DSAEK to evaluate the changes in the recipient-donor interface. ${ }^{18,19}$ Ide et al provided qualitative information on the presence of interface fluid following donor folding and insertion, ${ }^{18}$ while Knecht et al were able to quantify the amount of interface fluid following donor insertion with the Busin glide. ${ }^{19}$ Information on intraoperative changes in the recipient and the donor were not available in these studies.

The aim of the present study was to evaluate the use of SD-OCT in measuring the intraoperative changes in the donor lenticule, recipient cornea, and interface fluid thickness during DSAEK with EndoGlide ${ }^{\mathrm{TM}}$ (Angiotech Pharmaceuticals Inc, Vancouver, Canada) donor insertion.

\section{Methods}

This was a prospective observational case series of patients who underwent DSAEK at the Singapore National Eye Centre from May to July 2010. Informed consent was obtained from all patients recruited. The study was conducted in accordance with the tenets of the Declaration of Helsinki, and was approved by the local ethics committee.

\section{Surgical technique}

DSAEK was performed under general anesthesia by two surgeons (DT, JSM) using the Tan EndoGlide (Angiotech/ Network Medical Products, Ripon, United Kingdom) for donor insertion. ${ }^{20}$ The surgical technique has been described previously. ${ }^{20,21}$ In brief, a temporal scleral tunnel incision measuring $4.5 \mathrm{~mm}$ wide was made on the patient's eye, and an anterior chamber maintainer was preplaced one clock hour to the left of the main scleral tunnel. The Descemet's membrane was stripped under air with a Price hook (Moria SA, Antony, France). ${ }^{22}$ An inferior peripheral iridectomy was performed though a limbal stab incision. Four venting incisions were made on the recipient cornea. An automated lamellar therapeutic keratoplasty (ALTK) system (Moria, Antony, France) was used to perform lamellar dissection of the donor cornea, and the median size of trephination of $8.50 \mathrm{~mm}$ (range $8.25-9.00 \mathrm{~mm}$ ). The donor lenticule was inserted via the temporal scleral tunnel using the Tan EndoGlide. ${ }^{20} \mathrm{~A}$ clear cornea paracentesis was made in the nasal cornea directly across from temporal wound. A curved EndoGlide forceps (Network Medical Products), inserted into the anterior chamber through the nasal cornea paracentesis, was used to pull the graft from the EndoGlide into the anterior chamber. A small air bubble was injected beneath the graft after the graft was fully uncoiled in the anterior chamber with the endothelial surface down to prevent descent of the donor in the anterior chamber. The main sclera wound and the corneal incisions were sutured. The donor was then centralized by tapping and rubbing on the corneal surface. Air was then injected into the anterior chamber for a full air tamponade, and fluid was subsequently expressed from the venting incisions. After 10 minutes of full air tamponade, a smaller air bubble, which was slightly less than the graft diameter, was left in place at the end of the surgery. Postoperatively, patients were instructed to posture face-up with no pillow for 24 hours. Postoperative treatment comprised topical levofloxacin and prednisolone acetate every 3 hours.

\section{OCT imaging}

OCT imaging was performed in a dark room using a commercially available SD-OCT (iVue; Optovue Inc, Fremont, CA) with a handheld probe (Figure 1). Scanning speed was 26,000 axial scans per second and the image resolution was $5 \mu \mathrm{m}$. The anterior segment can be scanned up to a width of $6.0 \mathrm{~mm}$. Before image processing, scan images are modified after acquisition to provide dispersion compensation (dewarping, segmentation, and measurements). ${ }^{11}$ Intraoperative OCT imaging was performed by a single observer (FLG), who adjusted the saturation and noise and optimized the polarization of each scan to obtain the best quality image. The position of the SD-OCT handheld probe was adjusted to position the corneal vertex, identified by the Purkinje central corneal reflex, at the center of the OCT image. The standard anterior segment single-scan protocol was used, and more than one horizontal scan was obtained. The best quality scan, which did not have motion artifacts or artifacts caused by the eyelid margins, was chosen for measurements. To minimize speckle noise and to increase the signal-to-noise ratio, the final images were an averaged image of eight consecutive OCT frames. SD-OCT was used both qualitatively to search for interface fluid, which was drained selectively through the venting incisions, and quantitatively. In all patients, images were obtained during the following surgical stages of the DSAEK procedure: (1) after 


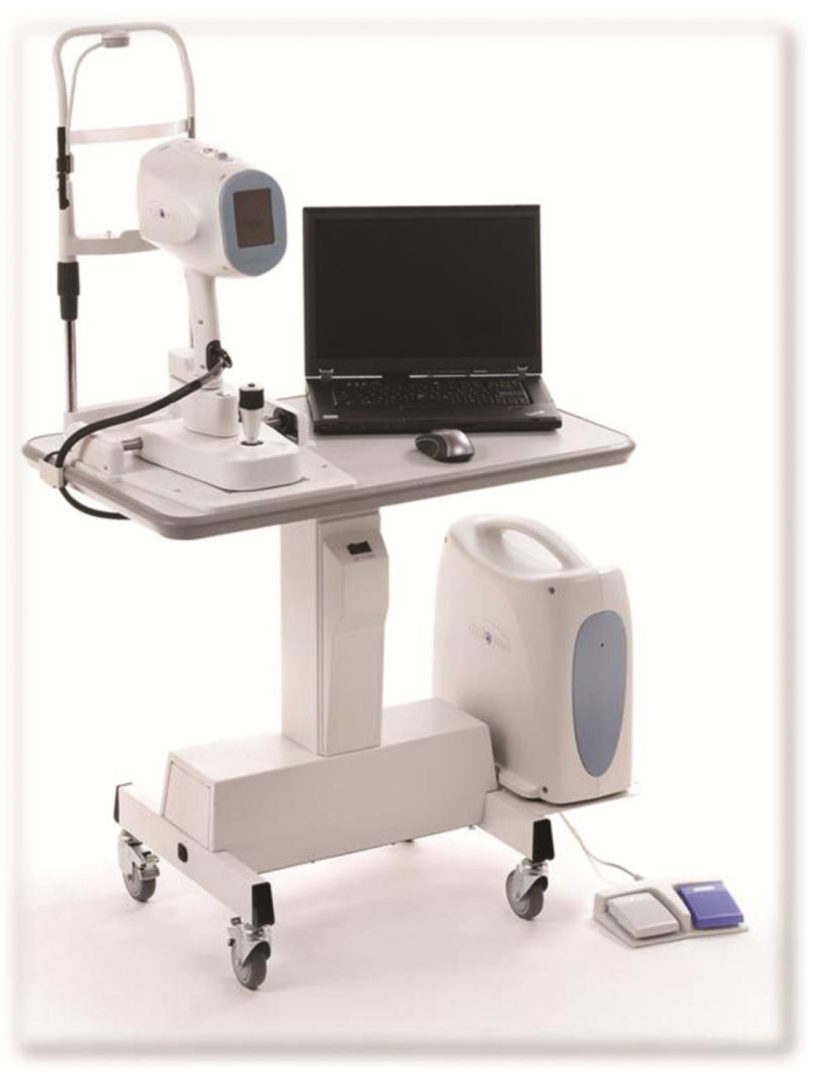

Figure I Photograph of the spectral-domain optical coherence tomography device used intraoperatively during Descemet's stripping and automated endothelial keratoplasty.

donor insertion and immediately prior to full air tamponade; (2) after air tamponade and expression of fluid from the venting incisions; (3) at 6 minutes of air tamponade; and (4) at 10 minutes of air tamponade to measure the donor, recipient, and interface fluid gap thicknesses. In one patient, SD-OCT imaging was performed after air tamponade and immediately before the expression of fluid from the venting incisions.

\section{Image analysis}

OCT images were analyzed by a single trained masked observer (FLG). The thickness of the interface fluid gap and donor and recipient cornea were measured using calipers provided by the SD-OCT software (iVue software version 1.9). Measurements were made at the reflective line which indicated the center of each horizontal scan. The mean of three measurements was calculated. It has previously been shown that the repeatability of SD-OCT measurements is excellent, with a mean standard deviation of only $4.19 \mu \mathrm{m} .{ }^{11}$

\section{Other ophthalmic investigations}

Intraoperative donor cornea thickness was measured with a portable pachymetry device (Corneo-Gage ${ }^{\mathrm{TM}}$ Plus multifunction pachymeter; Sonogage Inc, Cleveland, $\mathrm{OH}$ ) before the donor was inserted into the anterior chamber. Postoperative anterior segment imaging was performed with Visante ${ }^{\circledR}$ OCT (Carl Zeiss Meditec Inc, Dublin, CA) 1 month after DSAEK.

\section{Statistical analysis}

Statistical analysis was performed using IBM SPSS version 19.0 (SPSS Inc, Chicago, IL). Mixed models for repeated measures were used for the analysis. The dependent variable was the change in OCT measurements of the interface fluid gap, donor lenticule, and recipient cornea from that prior to air tamponade. The OCT measurement made at each surgical step (after expression of fluid though venting incisions, at 6 minutes of air tamponade, and at 10 minutes of air tamponade) was the repeated measure. Either first order autoregressive, compound symmetry, or unstructured was chosen as the mixed model variance-covariance structure as appropriate, based on Schwarz's Bayesian Criterion. $P<0.05$ was considered statistically significant.

\section{Results}

Ten patients with a mean age of $74.9 \pm 11.8$ years participated in this study. Four patients had a diagnosis of pseudophakic bullous keratoplasty and six patients had a diagnosis of Fuchs' endothelial dystrophy. There were no intraoperative or postoperative complications, and no complications occurred as a consequence of SD-OCT imaging. Graft detachment did not occur in any of the patients postoperatively.

The mean ultrasound pachymetry measurement of the central donor cornea thickness before lamellar dissection and trephination was $447.9 \pm 40.3 \mu \mathrm{m}$. After lamellar dissection and trephination, the mean posterior donor lenticule thickness measured using ultrasound pachymetry was $133.1 \pm 40.6 \mu \mathrm{m}$. Compared to SD-OCT measurements of the central donor thickness immediately prior to air tamponade, the donor thickness was significantly increased at 6 minutes of air tamponade $(282.9,95 \%$ confidence interval $237.5-328.4$ versus $239.5,95 \%$ confidence interval $194.0-285.0 \mu \mathrm{m} ; P=0.004)$. However, there was no statistically significant difference in donor thickness at 10 minutes of air tamponade compared to before air tamponade $(P=0.352)$. SD-OCT measurements of the recipient cornea and the interface fluid after fluid was expressed through the venting incisions $(P<0.001)$, at 6 minutes of air tamponade $(P<0.001)$ and at 10 minutes of air tamponade ( $P=0.001$ and $P<0.001$, respectively), were significantly decreased compared to the measurements immediately prior to air tamponade (Table 1, Figure 2). 
Table I Estimated mean thickness of the donor, recipient, and interface fluid at each surgical step during Descemet's stripping and endothelial keratoplasty

\begin{tabular}{|c|c|c|c|c|}
\hline \multirow[t]{2}{*}{ Surgical step } & \multirow[t]{2}{*}{$\begin{array}{l}\text { Estimated } \\
\text { mean thickness } \\
(\mu \mathrm{m})\end{array}$} & \multicolumn{2}{|c|}{$\begin{array}{l}95 \% \text { confidence interval } \\
\text { for estimated mean } \\
\text { thickness }(\mu \mathrm{m})\end{array}$} & \multirow[t]{2}{*}{$P *$} \\
\hline & & Lower & Upper & \\
\hline \multicolumn{5}{|l|}{ Donor (compound symmetry mixed model) } \\
\hline I. Immediately prior to air tamponade & 239.5 & 194.0 & 285.0 & NA \\
\hline 2. After fluid expression through venting incisions & 266.1 & 220.6 & 311.5 & $\begin{array}{l}0.102 \\
(1 \text { versus } 2)\end{array}$ \\
\hline 3. 6 minutes of air tamponade & 282.9 & 237.5 & 328.4 & $\begin{array}{l}0.004 \\
\text { (I versus 3) }\end{array}$ \\
\hline 4. 10 minutes of air tamponade & 220.7 & 175.2 & 266.2 & $\begin{array}{l}0.352 \\
\text { (I versus 4) }\end{array}$ \\
\hline \multicolumn{5}{|c|}{ Recipient (first order autoregressive mixed model) } \\
\hline I. Immediately prior to air tamponade & 674.7 & 624.9 & 724.5 & NA \\
\hline 2. After fluid expression through venting incisions & 606.3 & 556.1 & 656.5 & $\begin{array}{l}<0.001 \\
(1 \text { versus } 2)\end{array}$ \\
\hline 3. 6 minutes of air tamponade & 588.4 & 538.3 & 638.6 & $\begin{array}{l}<0.001 \\
(1 \text { versus } 3)\end{array}$ \\
\hline 4. 10 minutes of air tamponade & 581.9 & 532.1 & 631.7 & $\begin{array}{l}0.001 \\
(I \text { versus } 4)\end{array}$ \\
\hline \multicolumn{5}{|l|}{ Interface fluid (unstructured mixed model) } \\
\hline I. Immediately prior to air tamponade & 495.5 & 475.9 & 515.0 & NA \\
\hline 2. After fluid expression through venting incisions & 67.5 & 37.3 & 97.6 & $\begin{array}{l}<0.00 \mathrm{I} \\
(\mathrm{I} \text { versus } 2)\end{array}$ \\
\hline 3. 6 minutes of air tamponade & 33.0 & 24.6 & 41.4 & $\begin{array}{l}<0.00 \mathrm{I} \\
(\mathrm{I} \text { versus } 3)\end{array}$ \\
\hline 4. 10 minutes of air tamponade & 2.3 & 0.9 & 3.7 & $\begin{array}{l}<0.00 \mathrm{I} \\
(\mathrm{I} \text { versus } 4)\end{array}$ \\
\hline
\end{tabular}

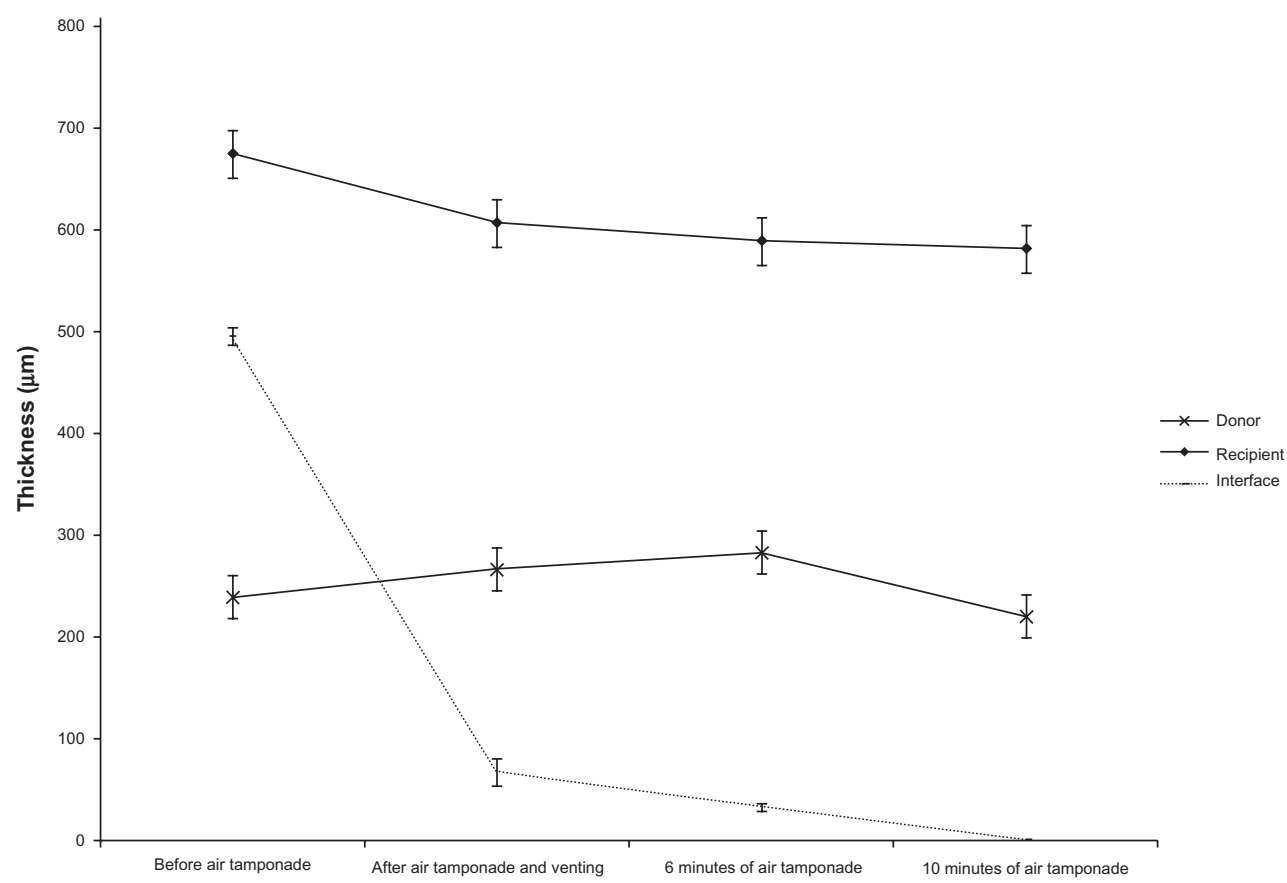

Figure 2 Intraoperative estimated mean thickness of the donor lenticule, recipient cornea, and interface fluid during Descemet's stripping and automated endothelial keratoplasty.

Note: *Error bars indicate standard error. 
Interface fluid was visualized using SD-OCT and drained selectively through venting incisions, resulting in $\leq 5 \mu \mathrm{m}$ of interface fluid gap thickness in all the patients after 10 minutes of air tamponade. In one patient who had SDOCT imaging after air tamponade and prior to venting, there was a decrease in interface fluid compared to the SD-OCT image immediately after venting (Figure 3 ).

One month after DSAEK, the mean thickness of the donor and recipient cornea measured using time-domain OCT was
$121.3 \pm 37.5 \mu \mathrm{m}$ and $524.9 \pm 33.7 \mu \mathrm{m}$, respectively. None of the patients had interface fluid between the donor and the recipient cornea 1 month after DSAEK.

\section{Discussion}

The results of this study indicate that the donor lenticule thickness increased initially following trephination and graft insertion with the EndoGlide, and subsequently reduced after 6 minutes of full air tamponade. In comparison, the

\section{A}

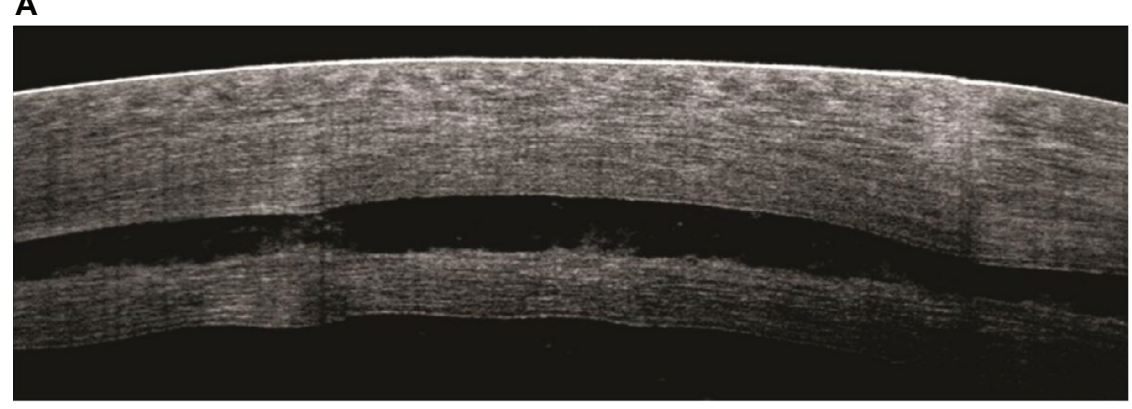

B

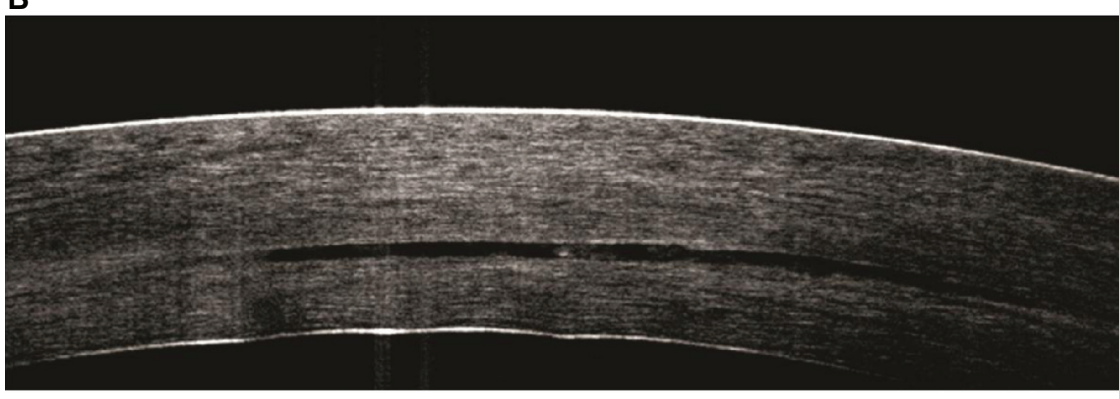

C

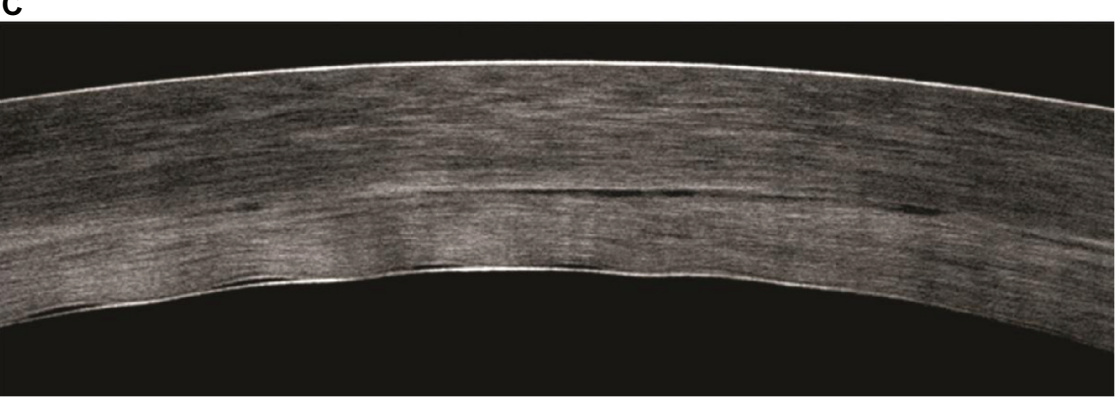

D

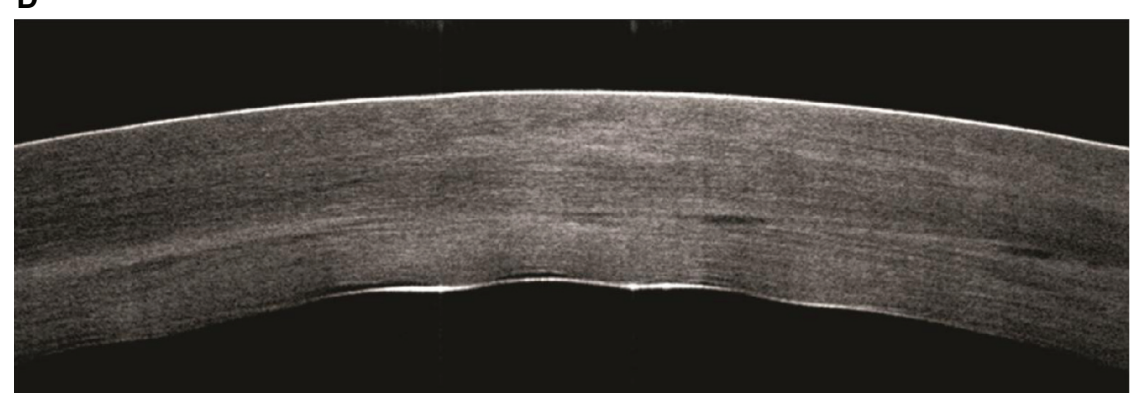

Figure 3 Intraoperative spectral-domain optical coherence tomography scans at the following surgical stages of Descemet's stripping and automated endothelial keratoplasty. (A) After donor insertion and immediately prior to full air tamponade. (B) After air tamponade and immediately prior to the expression of fluid from the venting incisions. (C) After the expression of fluid from the venting incisions. (D) At 6 minutes of air tamponade. No interface fluid can be detected in this patient at this stage. 
recipient cornea and interface fluid thickness decreased intraoperatively following donor insertion, venting, and air tamponade. Intraoperative SD-OCT is an effective imaging tool that allows the visualization of interface fluid and selective draining through venting incisions, hence ensuring full donor adherence at the conclusion of DSAEK.

The present study provides new data on the changes in SD-OCT measurements of the recipient cornea and donor lenticule during DSAEK with EndoGlide donor insertion, which have not been previously assessed. While the recipient cornea became thinner after venting and air tamponade, the donor thickness increased after trephination and insertion into the anterior chamber, and only decreased after 6 minutes of air tamponade. Compared to the ultrasound pachymetry measurements of donor thickness after trephination, SD-OCT measurements of the donor thickness increased after donor insertion and prior to air tamponade. As ultrasound pachymetry significantly overestimates corneal thickness measurements compared with SD-OCT,,$^{23,24}$ the amount of donor swelling after lamellar dissection and trephination was likely to be more than that presented in the present study. However, after 6 minutes of air tamponade, the donor thickness decreased, and this reduction in thickness continued postoperatively, as evidenced by the time-domain OCT measurements 1 month after DSAEK. Measurements made with time-domain OCT and SD-OCT have been shown to be comparable. ${ }^{25}$ There are a few possible reasons for the intraoperative decrease in donor thickness. First, the prolonged air tamponade may be a mechanical factor which promotes fluid egress through the interstitial spaces. Second, endothelial cells on the donor lenticule may already be functioning to pump fluid out of the cornea into the aqueous humor. This reversible intraoperative donor swelling in the patients suggests that there may be early endothelial function after donor insertion with the EndoGlide. This would be indicative of reduced cell loss during donor insertion with this device, which is supported by previously published rates of $13.1 \%$ cell loss at 6 months after DSAEK. ${ }^{20}$

Postoperative donor graft detachment is the most common complication encountered in DSAEK, with rates ranging from $17.5 \%$ to $50 \%$ being reported..$^{3-6}$ Potential causes of graft detachment include retained Descemet's membrane, ${ }^{26}$ endothelial cell damage which might compromise the adhesion of the graft to the recipient cornea, ${ }^{20,27}$ and eccentric trephination resulting in a thickened edge at one portion of the graft. ${ }^{4}$ Several methods for avoiding graft detachments have been proposed. Price and Price reported a decrease in the rate of graft detachment to $6 \%$ after the introduction of paracentral full-thickness venting incisions, through which interface fluid can be removed. ${ }^{6}$ However, venting incisions have been associated with potentially sight-threatening complications, such as epithelial ingrowth. ${ }^{5,28-30}$ They may also may be a portal of entry for pathogens, leading to corneal and intraocular infections..$^{31}$ Terry et al suggested that venting incisions may be unnecessary, and rates of graft detachment can be reduced by roughening the recipient stromal surface before placement of the graft. ${ }^{32}$ However, a prospective study comparing the rates of graft detachment between recipient corneas with venting incisions and for recipient surfaces that have been roughened has not been performed. The current surgical technique of graft insertion with the EndoGlide, complete wound closure prior to air tamponade, at least 10 minutes of compressive air tamponade, and the removal of fluid through venting incisions has resulted in a low rate of graft detachment of less than $3 \% .{ }^{33}$ Results from the present study show that both the interface fluid gap and recipient cornea thicknesses decreased significantly after venting and air tamponade. In one patient who had SD-OCT imaging immediately before and after venting, it was evident that the removal of fluid through venting incisions resulted in a decrease in the interface fluid gap. This provides further evidence that venting, in conjunction with air tamponade, can enhance donor attachment.

Intraoperative OCT imaging of the interface fluid has been reported by two previous studies. Ide et al developed a prototype anterior segment SD-OCT which had an axial resolution of $8 \mu \mathrm{m} .{ }^{18} \mathrm{After}$ donor insertion using the folding technique, the prototype SD-OCT was used intraoperatively in six patients to search for interface fluid which was clinically undetectable under a coaxial operating microscope. If present, the interface fluid was aspirated before the end of the surgery, and graft detachment did not occur in any of the patients. While a microscope with a slit beam would also offer the ability to qualitatively assess the presence of interface fluid, it may be unable to detect small quantities of fluid and is not able to provide quantitative measurements of the amount of fluid. In an observational study, interface fluid was quantified intraoperatively during DSAEK using a handheld Fourier-domain OCT (Bioptigen Inc, Durham, $\mathrm{NC}$ ), which has a resolution of $10 \mu \mathrm{m}$. Knecht et al showed that after donor insertion with the Busin glide and subsequent venting, donor adherence can occur in spite of residual interface fluid of less than $0.2 \mu \mathrm{m} .{ }^{19}$ The use of a higher resolution SD-OCT of $5 \mu \mathrm{m}$ in the present study indicates that donor adherence is possible even when up to $5 \mu \mathrm{m}$ of interface fluid is present centrally. 
The present study has clinical implications which may be useful. The findings highlight the potential role of SD-OCT, which is commercially available, in facilitating intraoperative decision making. This is especially important during DSAEK when the surgeon's view of the donor-recipient interface can be obstructed due to marked corneal edema or in previous penetrating keratoplasty cases due to the graft-host junction. SD-OCT can be used to search for pockets of interface fluid intraoperatively, which can be drained selectively through the venting incisions before the patient leaves the operating room. The donor thickness increased intraoperatively and decreased only after 6 minutes of air tamponade, and this has not been previously described. The intraoperative use of SD-OCT has significant implications not only for DSAEK, but also for deep anterior lamellar keratoplasty. When the residual stroma bed is too thin to be measured by conventional ultrasound pachymetry, SD-OCT can aid in determining the depth of the predescemetic dissections. It may also help in the placement of a blunt cannula or needle into the posterior stroma to form a "big bubble," so as to cleave the Descemet's membrane from the overlying stroma. ${ }^{34,35}$

The strengths of the present study include the use of a high resolution commercially available SD-OCT and the statistical analysis of intraoperative changes in SD-OCT measurements, which have not been previously performed. However, a limitation of the study was the small sample size, but this was a pilot study which aimed primarily to demonstrate the intraoperative utility of SD-OCT.

In conclusion, it has been shown that SD-OCT is able to detect significant intraoperative changes in the interface fluid gap, donor, and recipient cornea thicknesses during DSAEK. Further studies are needed to evaluate the intraoperative utility of SD-OCT during other surgical procedures, including deep anterior lamellar keratoplasty.

\section{Disclosure}

The SD-OCT was on loan from Optovue (iVue; Optovue Inc, Fremont, CA). Jodhbir Mehta and Donald Tan have a commercial interest in the Tan EndoGlide ${ }^{\text {TM }}$ (Network Medical Products, Ripon, United Kingdom).

\section{References}

1. Price FW Jr, Price MO. Descemet's stripping with endothelial keratoplasty in 50 eyes: a refractive neutral corneal transplant. J Refract Surg. 2005;21(4):339-345.

2. Gorovoy MS. Descemet-stripping automated endothelial keratoplasty. Cornea. 2006;25(8):886-889.

3. Lee WB, Jacobs DS, Musch DC, Kaufman SC, Reinhart WJ, Shtein RM. Descemet's stripping endothelial keratoplasty: safety and outcomes: a report by the American Academy of Ophthalmology. Ophthalmology. 2009;116(9):1818-1830.
4. Suh LH, Yoo SH, Deobhakta A, et al. Complications of Descemet's stripping with automated endothelial keratoplasty: survey of 118 eyes at One Institute. Ophthalmology. 2008;115(9):1517-1524.

5. Shih CY, Ritterband DC, Rubino S, et al. Visually significant and nonsignificant complications arising from Descemet stripping automated endothelial keratoplasty. Am J Ophthalmol. 2009;148(6): $837-843$.

6. Price FW Jr, Price MO. Descemet's stripping with endothelial keratoplasty in 200 eyes: early challenges and techniques to enhance donor adherence. J Cataract Refract Surg. 2006;32(3):411-418.

7. Radhakrishnan S, Rollins AM, Roth JE, et al. Real-time optical coherence tomography of the anterior segment at $1310 \mathrm{~nm}$. Arch Ophthalmol. 2001;119(8):1179-1185.

8. Sng CC, See JS, Ngo CS, et al. Changes in retinal nerve fibre layer, optic nerve head morphology, and visual field after acute primary angle closure. Eye (Lond). 2011;25(5):619-625.

9. Yuen LH, He M, Aung T, Htoon HM, Tan DT, Mehta JS. Biometry of the cornea and anterior chamber in Chinese eyes: an anterior segment optical coherence tomography study. Invest Ophthalmol Vis Sci. 2010;51(7):3433-3440.

10. Sng CC, Singh M, Chew PT, et al. Quantitative assessment of changes in trabeculectomy blebs after laser suture lysis using anterior segment optical coherence tomography. J Glaucoma. May 10, 2011. [Epub ahead of print.]

11. Hall RC, Mohamed FK, Htoon HM, Tan DT, Mehta JS. Laser in situ keratomileusis flap measurements: comparison between observers and between spectral-domain and time-domain anterior segment optical coherence tomography. J Cataract Refract Surg. 2011;37(3):544-551.

12. Lim LS, Aung HT, Aung T, Tan DT. Corneal imaging with anterior segment optical coherence tomography for lamellar keratoplasty procedures. Am J Ophthalmol. 2008;145(1):81-90.

13. Costa RA, Skaf M, Melo LA Jr, et al. Retinal assessment using optical coherence tomography. Prog Retin Eye Res. 2006;25(3):325-353.

14. Huang D, Swanson EA, Lin CP, et al. Optical coherence tomography. Science. 1991;254(5035):1178-1181.

15. Lu AT, Wang M, Varma R, et al. Combining nerve fiber layer parameters to optimize glaucoma diagnosis with optical coherence tomography. Ophthalmology. 2008;115(8):1352-1357.

16. Mistlberger A, Liebmann JM, Greenfield DS, et al. Heidelberg retina tomography and optical coherence tomography in normal, ocular-hypertensive, and glaucomatous eyes. Ophthalmology. 1999;106(10):2027-2032.

17. Di Pascuale MA, Prasher P, Schlecte C, et al. Corneal deturgescence after Descemet stripping automated endothelial keratoplasty evaluated by Visante anterior segment optical coherence tomography. Am J Ophthalmol. 2009;148(1):32-37.

18. Ide T, Wang J, Tao A, et al. Intraoperative use of three-dimensional spectral-domain optical coherence tomography. Ophthalmic Surg Lasers Imaging. 2010;41(2):250-254.

19. Knecht PB, Kaufmann C, Menke MN, Watson SL, Bosch MM. Use of intraoperative Fourier-domain anterior segment optical coherence tomography during Descemet stripping endothelial keratoplasty. Am J Ophthalmol. 2010;150(3):360-365.

20. Khor WB, Mehta JS, Tan DT. Descemet stripping automated endothelial keratoplasty with a graft insertion device: surgical technique and early clinical results. Am J Ophthalmol. 2011;151(2):223-232.

21. Gimeno FL, Lang M, Mehta JS, Tan DT. Descemet's stripping automated endothelial keratoplasty: past, present and future. Exp Rev Ophthalmol. 2010;5(3):303-311.

22. Mehta JS, Hantera MM, Tan DT. Modified air-assisted descemetorhexis for Descemet-stripping automated endothelial keratoplasty. J Cataract Refract Surg. 2008;34(6):889-891.

23. Ishibazawa A, Igarashi S, Hanada K, et al. Central corneal thickness measurements with Fourier-domain optical coherence tomography versus ultrasonic pachymetry and rotating Scheimpflug camera. Cornea. 2011;30(6):615-619. 
24. Li Y, Tang M, Zhang X, Salaroli CH, Ramos JL, Huang D. Pachymetric mapping with Fourier-domain optical coherence tomography. J Cataract Refract Surg. 2010;36(5):826-831.

25. Huang JY, Pekmezci M, Yaplee S, Lin S. Intra-examiner repeatability and agreement of corneal pachymetry map measurement by timedomain and Fourier-domain optical coherence tomography. Graefes Arch Clin Exp Ophthalmol. 2010;248(11):1647-1656.

26. Kymionis GD, Suh LH, Dubovy SR, Yoo SH. Diagnosis of residual Descemet's membrane after Descemet's stripping endothelial keratoplasty with anterior segment optical coherence tomography. J Cataract Refract Surg. 2007;33(7):1322-1324.

27. Terry MA, Chen ES, Shamie N, Hoar KL, Friend DJ. Endothelial cell loss after Descemet's stripping endothelial keratoplasty in a large prospective series. Ophthalmology. 2008;115(3):488-496.

28. Koenig SB, Covert DJ. Epithelial ingrowth after Descemetstripping automated endothelial keratoplasty. Cornea. 2008;27(6): 727-729.

29. Prasher P, Muftuoglu O, Hsiao ML, Bowman RW, Hogan RN, Mootha VV. Epithelial downgrowth after Descemet stripping automated endothelial keratoplasty. Cornea. 2009;28(6):708-711.
30. Suh LH, Shousha MA, Ventura RU, et al. Epithelial ingrowth after Descemet stripping automated endothelial keratoplasty: description of cases and assessment with anterior segment optical coherence tomography. Cornea. 2011;30(5):528-534.

31. Chew AC, Mehta JS, Li L, Busmanis I, Tan DT. Fungal endophthalmitis after Descemet stripping automated endothelial keratoplasty - a case report. Cornea. 2010;29(3):346-349.

32. Terry MA, Hoar KL, Wall J, Ousley P. Histology of dislocations in endothelial keratoplasty (DSEK and DLEK): a laboratory-based, surgical solution to dislocation in 100 consecutive DSEK cases. Cornea. 2006;25(8):926-932.

33. Tan GS, Mehta JS, Tan D. Descemet stripping automated endothelial keratoplasty in Asian eyes: one-year results. Paper presented at: American Society of Cataract and Refractive Surgeons Symposium and Congress; 2011; March 25-29; San Diego, CA. Poster no.: P264.

34. Anwar M, Teichmann KD. Big-bubble technique to bare Descemet's membrane in anterior lamellar keratoplasty. J Cataract Refract Surg. 2002;28(3):398-403

35. Tan DT, Anshu A. Anterior lamellar keratoplasty: "Back to the Future"a review. Clin Experiment Ophthalmol. 2010;38(2):118-127.
Clinical Ophthalmology

\section{Publish your work in this journal}

Clinical Ophthalmology is an international, peer-reviewed journal covering all subspecialties within ophthalmology. Key topics include: Optometry; Visual science; Pharmacology and drug therapy in eye diseases; Basic Sciences; Primary and Secondary eye care; Patient Safety and Quality of Care Improvements. This journal is indexed on

\section{Dovepress}

PubMed Central and CAS, and is the official journal of The Society of Clinical Ophthalmology (SCO). The manuscript management system is completely online and includes a very quick and fair peer-review system, which is all easy to use. Visit http://www.dovepress.com/ testimonials.php to read real quotes from published authors. 